\title{
Changes in Pre-Service Teachers' Beliefs about Mathematics Teaching and Learning during Teacher Preparation and Effects of Video-Enhanced Analysis of Practice
}

\author{
Sonja Mohr \\ Rossella Santagata \\ University of California, School of Education
}

Technical University of Berlin, Humanities, Institute of Education

\begin{abstract}
While the construct belief is defined in various ways in teacher education research, most scholars agree that beliefs guide teachers' decision making and classroom behaviors and thus are an important aspect of teacher competence. Pre-service teachers (PSTs) have been typically found to hold a transmission view of mathematics teaching. The influence of teacher preparation on future teachers' beliefs about mathematics teaching and learning is unclear. This study investigates beliefs in a sample of U.S. elementary PSTs prior to teacher preparation and examines the impact on belief changes of two different mathematics methods courses. Findings reveal that while PSTs hold a transmission view of mathematics teaching prior to teacher preparation, their beliefs change during the program. In addition, PSTs who attended a video-enhanced mathematics methods course structured around systematic and collaborative analysis of practice showed stronger evidence of alignment with the beliefs that children can solve problems in novel ways before being taught how to solve such problems and that teachers should allow children to do as much of the thinking as possible during instruction, than a group of PSTs who attended a more typical version of the course. Implications for teacher preparation and future research are discussed.
\end{abstract}

Keywords: pre-service teachers, beliefs, mathematics teaching, video

DOI: $10.14712 / 23363177.2015 .82$

This paper summarizes the findings of a study that examined pre-service elementary teachers' (PSTs) beliefs about mathematics teaching and learning prior to and at the end of teacher preparation. Building on recent research on teacher beliefs, the present study investigates two approaches to teacher preparation and their impact on belief change.

Beliefs in the context of research on teacher learning have been described as a "messy construct" (Pajares, 1992, p. 307) because of the variety of meanings different scholars attribute to the term. Despite disagreements on the definition of

* This research was supported by the National Science Foundation (Research and Evaluation on Education in Science and Engineering [REESE] Program) under Grant DRL-0953038. Any opinions, findings, and conclusions expressed in this material are those of the authors and do not necessarily express the views of the National Science Foundation. The authors thank the participating teachers and are grateful to Janet Mercado, Cathery Yeh, and several undergraduate students who served as research assistants and scored teachers' survey responses. 
104 the term belief, most agree that teacher beliefs are acquired during past schooling and are thus outlasting propositions which can be consciously or unconsciously held. Beliefs are evaluative and subjective in nature and function as a guide to teachers' thought and behavior (Blömeke, 2012; de Fries, 2013; Pajares, 1992). Richardson (1996, p. 103) defined beliefs as "understandings, premises, or propositions about the world that are felt to be true." Their subjective character makes them distinguishable from teacher knowledge. Nevertheless, their guiding function makes them not less important in terms of teachers' decision making and teaching behavior (Schoenfeld, 2011). This point is also stressed by Ambrose et al. (2004) who have developed an innovative measure of teacher beliefs about mathematics teaching and learning that we used in the study summarized here. These authors argue that teacher beliefs possess four characteristics: 1) they influence perception; 2) they are dispositions to actions; 3) they are held with differing intensities; and 4) they tend to be context-specific. In our research on teacher learning we embrace this view of beliefs and we examine whether and under which conditions teacher beliefs are changeable.

\section{State of research on pre-service teachers' beliefs and belief changes during teacher preparation}

According to a review of research on PSTs' beliefs (Handal, 2003), PSTs hold a traditional set of beliefs at the beginning of teacher preparation. Their beliefs rely on their experiences in school and are not theory and knowledge-oriented. Accordingly, they often overvalue "the role of memorization of rules and procedures in the learning and teaching of school mathematics" (Handal, 2003, p. 50).

Although beliefs are often seen as stable and unchangeable, teacher preparation programs (at least those informed by research on mathematics teaching and learning) mostly attempt to shift PSTs' beliefs from traditional to progressive, that is towards a dynamic view of mathematics that values the process of inquiry and a constructivist point of view (Handal, 2003; Op’t Eynde, de Corte, \& Verschaffel, 2002).

Several longitudinal studies have been conducted to assess effects of teacher preparation and belief change of PSTs during teacher education. The results are inconsistent: some studies do not report any changes and intervention effects (Benbow, 1995; Foss \& Kleinsasser, 1996), whereas more recent studies show that PSTs develop a more constructivist point of view during teacher preparation. For example, Biedermann, Brühwiler and Steinmann (2012) found that experienced PSTs saw mathematics as a process of inquiry rather than a set of rules and procedures, and they preferred active learning processes rather than teacher centered instruction to a greater extent than PSTs at the beginning of teacher preparation.

Different opportunities to learn are seen as important to foster belief change. Positive intervention effects have been detected when videos have been used to foster belief change or when field placements have been carefully designed and effective mentors provided (Blömeke et al., 2008; Philipp et al., 2007; Swars et al., 2012). 
Video is used extensively in teacher preparation and professional development to situate teacher learning in the context of classroom practice (Borko et al., 2008). Video can serve as a common referent to ground future teachers' discussions of classroom teaching (Santagata \& Guarino, 2011). New technologies allow for easy review of digital footage; the same excerpts can be watched several times to unpack important teaching-learning moments and detail features of teaching moves that might be unfamiliar to observers. An advantage of video over fieldwork observations is that teacher educators can control what PSTs are exposed to and guide their viewing and discussions to highlight particular features of teaching practices (Santagata, Zannoni, \& Stigler, 2007). The examination of PSTs' beliefs about teaching and learning and how these might change as a result of using video strategically in teacher preparation is an under-studied area of research (Wang \& Hartley, 2003).

One of the few studies on this topic was conducted by Philipp et al. (2007). These authors developed a measure of teacher beliefs about mathematics teaching and learning - the IMAP Web-Based Beliefs Survey (we used the same measure in the present study). They analyzed belief change in PSTs attending four different kinds of field experiences that focused on: 1) learning about children's mathematical thinking by watching videos, 2 ) watching videos about children's mathematical thinking and working directly with individual children on problem solving, 3) visiting teachers with classroom close to the university, or 4) visiting selected teachers identified as reform oriented. A control group did not undergo any experiences. Results indicate that PSTs who learned about children's mathematical thinking either through watching videos only, or through a combination of video analysis and direct work with children showed larger belief changes than all other PSTs. Interestingly, the belief change of the control group was larger than for the PSTs who visited typical mathematics classrooms, close to the university. The authors argue that experiences in these classrooms might contradict the beliefs that are promoted in university courses during teacher preparation. Thus this study's findings indicate that a focus on the analysis of children mathematical thinking during teacher preparation supports changes in beliefs. In addition, video can be used as an effective tool to change beliefs that can substitute PSTs direct work with children. Field experiences in classrooms that are not necessarily aligned with constructivist approaches to mathematics teaching, on the other hand, can be counterproductive. Accordingly, the authors argue for an approach to teacher preparation that a) controls for variables that might otherwise distract PSTs, b) maintains sufficiently authentic experiences that PSTs found relevant to their future work as teachers (as it can be done with video recordings), and c) provides PSTs opportunities for guided reflection (Philipp et al., 2007).

\section{Study design}

We build on the Philipp et al.'s study (2007) to examine the impact of a video-enhanced mathematics methods course on changes in PSTs' beliefs about mathematics 
teaching and learning. In order to compare our findings with the results of Philipp et al.'s (2007), we used the same instrument to measure PSTs beliefs (see Measure section).

This study is part of a larger project that includes an experimental design. Participants are PSTs enrolled in a teacher preparation program for elementary school teachers (teaching kindergarten through sixth grade, that is children from 5 to 12 years old) at a large public university in the United States. PSTs were randomly assigned to attend two 20-week mathematics methods courses that differed in their approach. Both mathematics methods courses were taught in the fall (mid-September till December) and winter (January till mid-March) quarters by expert instructors, who had several years of teaching experience both at primary-school and teacher-preparation levels.

The courses met for approximately 30 hours each quarter, structured in 3-hour weekly meetings. The experimental course, hereby named the Learning from Mathematics Teaching (LMT) course, made extensive use of video as a tool for developing PSTs' abilities to analyze teaching and students' learning. It combined activities that allowed the study and analysis of teaching with opportunities to practice student-centered teaching with students in classroom settings. Video was used to provide images of mathematics teaching that is responsive to student thinking and to facilitate a collaborative process of analysis. Similarly to the intervention in the Philipp et al.' study (2007), PSTs reviewed videos of individual students solving mathematics problems. In addition, the course included analyses of classroom teaching episodes. A framework tested in previous studies, the Lesson Analysis Framework (Santagata \& Guarino, 2011) guided PSTs' collaborative analysis of student thinking, mathematical ideas, and the interrelation between teachers' decisions and student learning. As PSTs watched videos of classroom lessons, they were asked to attend to the following four sets of questions: 1) What is the main learning goal of this instructional episode? 2) Did the students make progress toward the learning goals? What evidence do we have that students made progress? What evidence do we have that students did not make progress? What evidence are we missing? 3) Which instructional strategies supported students' progress toward the learning goals and which did not? Finally 4) What alternative strategies could the teacher use? How do you expect these strategies to impact students' progress toward the lesson learning goals? If any evidence of student learning is missing, how could the teacher collect such evidence?

Video-enhanced tasks were planned to gradually scaffold PSTs from supported to independent analyses of teaching and from analyses of others' lessons to analysis of their own teaching. Thus, even though the development of PSTs' ability to analyze student thinking was a concern shared between our intervention and those designed by Philipp et al.'s (2007), our course was broader in scope in that, as a mathematics methods course, its ultimate objective was that of preparing teachers to teach mathematics and to reflect on their own teaching in productive ways.

It is plausible to think that, although PSTs' beliefs were not explicitly the focus of the video-enhanced collaborative analyses we designed, these analyses served as opportunities for PSTs to confront their beliefs about mathematics teaching and 
learning. This is the question we entertain in the present study. In a previous implementation of a similar curriculum, we found that PSTs spent a considerable amount of time during group discussions comparing the mathematics teaching approach promoted by the mathematics methods instructor and the approach they experienced as children. Over time statements that challenged the constructivist approach to mathematics teaching decreased and statements that embraced it increased in number (Santagata, Jovel \& Yeh, under review).

The comparison course, hereby named the Mathematics Methods Course (MMC), also promoted a constructivist and student-centered approach to mathematics teaching, but followed a more typical approach to mathematics methods instruction in the United States. It focused on developing teachers' mathematics content and pedagogy, problem-based instructional strategies, lesson planning, and assessments. Video was seldom used and PSTs did not engage in systematic analysis of student thinking and learning.

Both groups of PSTs completed a fieldwork experience while attending the math methods course and during the subsequent spring quarter (i.e., April through June). During the fall quarter they observed a master teacher once a week and engaged in brief, highly-supported teaching activities. During the winter quarter, they spent four days a week in the classroom and gradually assumed more teaching responsibility. During the spring quarter, they changed placement (moving to a higher grade level (4th-6th grade) if they were placed in a k-3 grade class during the fall and winter, or moving to a lower grade level if they were placed in an upper grade level class during the fall and winter) and assumed full responsibility for the class. Field placements were made randomly. It is thus plausible to assume that the quality of the placement (i.e., nature of support provided by the master teacher and teaching approach prevalent in the placement class) varied equally across groups.

\section{Research questions}

The present study focused on two sets of research questions:

1. What is the nature of PSTs' beliefs about mathematics teaching and learning prior to teacher preparation?

2. Do PSTs' beliefs change during teacher preparation? What is the nature of PSTs' beliefs at the end of teacher preparation in the two groups of participants? Are there significant group differences?

\section{Measure}

To measure beliefs, the Integrating Mathematics and Pedagogy survey (IMAP) developed by Ambrose et al. (2004) was used. Participants completed the survey prior to the beginning of the course and approximately three months after course completion 
108 (i.e., at the end of their spring student teaching placement). This is a web-based survey developed to assess prospective elementary teachers' beliefs about mathematics teaching and learning. The survey utilizes context-specific item prompts in a constructed response test format. It portrays complex classroom situations (either described through words and students' work or portrayed in video clips) involving students that capture the uncertainty of elementary classroom interactions. PSTs are asked to analyze and respond to these complex situations through a combination of close and open-ended items.

This approach to measuring teacher beliefs departs from more commonly used measures based on Likert-scale surveys. IMAP survey designers pointed out three issues with measures using Likert-scales only: 1 ) it is difficult to know how respondents interpret words used in the survey items, 2) survey responses do not provide information about the importance of a certain issue to respondents, and 3) little or no context is provided, leading to possible multiple interpretations of a statement. To address these issues and build on the most recent literature on teacher beliefs, the IMAP survey was designed to take into account the four characteristics of beliefs mentioned above: 1) beliefs influence perception, therefore surveys should include complex situations to interpret; 2 ) beliefs are dispositions to actions, therefore they can be inferred from ways respondents are disposed to act in a particular situation; 3 ) beliefs are held with differing intensities, therefore surveys should capture differing levels of evidence for a respondent's holding a belief; and 4) beliefs tend to be context-specific, thus surveys should situate questions in context and infer respondents' beliefs based on their interpretations on the situation (Philipp, 2007).

The beliefs targeted by the survey are phrased from a constructivist point of view. In this study, because of time issues we were not able to assess all seven IMAP beliefs. Instead we focused on the four that were most aligned with our intervention:

Belief 1: Mathematics is a web of interrelated concepts and procedures (and school mathematics should be too).

Belief 2: If students learn mathematical concepts before they learn procedures, they are more likely to understand the procedures when they learn them. If they learn the procedures first, they are less likely ever to learn the concepts.

Belief 3: Children can solve problems in novel ways before being taught how to solve such problems. Children in primary grades generally understand more mathematics and have more flexible solution strategies than adults expect.

Belief 4: During interactions related to the learning of mathematics, the teacher should allow the children to do as much of the thinking as possible.

Each belief is measured through a set of questions. For example, PSTs are asked to: evaluate student solution strategies to a problem and their connections and decide which strategies they would share in a class discussion and why; adopt the teacher's role and consider different strategies for multi-digit addition; select and justify an order for discussing particular strategies during a unit on multi-digit addition, including solutions that represented the standard algorithm and solutions that were more conceptual in nature; discuss whether a child could solve a particular novel problem 
on his own without a step-by-step explanation; and watch brief video clips of a student-teacher interaction and discuss the role of the teacher (who was portrayed to be very leading), and ways they would have structured the lesson, including whether they would have built on students' thinking to a greater extent than the observed teacher.

Responses are scored according to the instrument's manual (Philipp \& Schappelle, 2003) and are assigned a score of 0 if interpreted as showing no evidence of the belief and the highest score possible (a score of 3 for Beliefs 1, 2, and 4 and a score of 4 for Belief 3) if they indicate (very) strong evidence of the belief. The combination of scores obtained in questions targeting a certain belief provide an overall score for that belief. The survey authors chose to use a maximum score of 4 for Belief 3 because of the wider range of teacher responses and levels of evidence that these provided.

Two independent raters scored all responses. Inter-rater reliability, measured as percent agreement, for all sets of questions was computed initially, at midpoint, and at the end of scoring and ranged from $80 \%$ to $95.8 \%$ across questions and time points. In case of disagreements, a third rater reviewed the response and made the final scoring decision.

\section{Participants}

The study participants included 112 elementary PSTs, two cohorts (2011/12 and 2012/13 academic years) of the one year post-bachelor teacher education program from which the participants were drawn. PSTs were randomly assigned to the LMT $(N=53)$ or the MMC group $(N=59)$. Differences in sample size are due to a few participants who left the program for health issues right after random assignment was completed or decided not to participate in the study. Of the 112 participants, 48 from the LMT and 47 from the MMC course had both pre and post survey data. Eighty-nine percent of the participants were female with an average age of 23.5 years (SD = 2.82 years). PSTs identified themselves as Caucasian American (47.3\%), Asian American (39.3\%), Latin American (8\%), and other (5.4\%). 51.4\% held bachelor's degrees in the humanities, $45.0 \%$ in social sciences, $2.7 \%$ in business, $0.45 \%$ in biological sciences. Only one participant held a bachelor degree in mathematics. Finally, approximately half $(47 \%)$ of the participants had no prior teaching experience. The rest had minimal teaching experiences (i.e. tutoring, coaching).

\section{Results}

In summarizing the study results we will answer the research questions one at a time. PSTs were randomly assigned to either the LMT or MMC course. Initially, differences in the incoming belief scores of PSTs in the LMT and MMC group were analyzed to assure that preconditions were equal in both groups. Mann-Whitney-U-Tests were used because of the skewness and ordinal structure of the data. The median was 
110 calculated for each belief. No differences between the LMT and MMC group prior to teacher preparation were found. All participants showed overall weak alignment with constructivist beliefs.

Figure 1 below presents the percentages of PSTs that showed different levels of alignment with each of the four measured beliefs at the beginning of teacher preparation. For Belief 1 (i.e., mathematics is a web of interrelated concepts and procedures; $M d n=1.00$ ) as well as Belief 3 (i.e., Children can solve problems in novel ways before being taught how to solve such problems. Children in primary grades generally understand more mathematics and have more flexible solution strategies than adults expect; $M d n=1.00$ ) most of the participants showed no or weak alignment. For Belief 2 (i.e., if students learn mathematical concepts before they learn procedures, they are more likely to understand the procedures when they learn them. If they learn the procedures first, they are less likely ever to learn the concepts; $M d n=1.00$ ), a little over half of the participants showed no evidence or weak evidence of alignment. Finally, for Belief 4 (i.e., during interactions related to the learning of mathematics, the teacher should allow the children to do as much of the thinking as possible; Mdn $=0.00$ ) the least alignment was found ( $60 \%$ showed no evidence of alignment), making this belief an important one to focus on in teacher preparation.

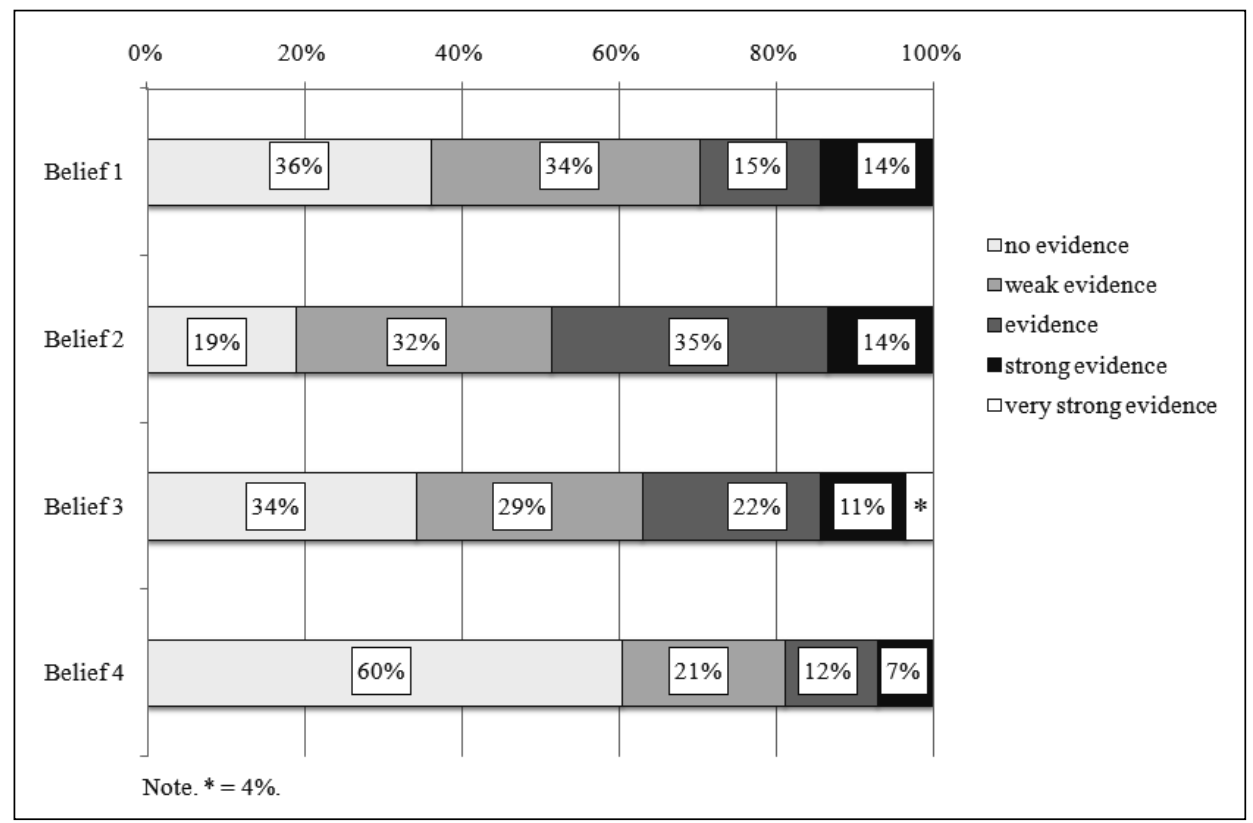

Figure 1 Percentage of participants who showed different levels of alignment with the beliefs measured by the IMAP survey at the beginning of teacher preparation

To assess changes in PSTs' beliefs during teacher preparation, Spearman correlations were performed for both LMT and MMC groups as a measure of score stability 
over time (see Table 1). All correlations were low and not significant; this showed that stability of scores was low. Consequently, scores changed considerably from the beginning to the end of teacher preparation.

Table 1 Spearman correlations between belief alignment prior to and at the end of teacher preparation for each group

\begin{tabular}{lcccc} 
& Belief 1 & Belief 2 & Belief 3 & Belief 4 \\
\hline $\begin{array}{l}\text { LMT group } \\
\text { Corr. Coeff. }\end{array}$ & .010 & .047 & .165 & -.003 \\
\hline $\begin{array}{l}\text { MMC group } \\
\text { Corr. Coeff. }\end{array}$ & .236 & .036 & .155 & .073 \\
\hline
\end{tabular}

Note: LMT group $(\mathrm{N}=48)$, MMC group $(\mathrm{N}=47)$; Spearman-Correlations, not significant.

To further assess these changes, change scores were calculated following the procedure suggested by Philipp et al. (2007, p. 453f.). Accordingly, PSTs (LMT vs. MMC group) were categorized into one of three groups based on their belief changes: 1 ) PSTs whose belief scores did not increase or decrease; 2) PSTs whose belief scores went up one level (small increase); and 3) PSTs whose belief scores went up two or more levels (large increase). The change scores are presented in Table 2.

Table 2 Belief changes by group and change score category

\begin{tabular}{lccc}
\hline & No increase or decrease & Small increase & Large increase \\
\hline Belief 1 & & & \\
\hline LMT group & $38 \%$ & $29 \%$ & $33 \%$ \\
MMC group & $45 \%$ & $25 \%$ & $30 \%$ \\
Belief 2 & & & \\
\hline LMT group & $29 \%$ & $35 \%$ & $35 \%$ \\
MMC group & $32 \%$ & $34 \%$ & $34 \%$ \\
Belief 3 & & & \\
\hline LMT group & $35 \%$ & $19 \%$ & $28 \%$ \\
MMC group & $40 \%$ & $32 \%$ & $31 \%$ \\
\hline Belief 4 & & & $19 \%$ \\
\hline LMT group & $33 \%$ & $35 \%$ & \\
MMC group & $53 \%$ & $28 \%$ & \\
\hline
\end{tabular}

Considerable changes were found for PSTs in both groups. Figure 2 shows the percentages of different levels of evidence in PSTs' alignment with the beliefs at the end of teacher preparation. Despite the fact that PSTs' beliefs changed in all four belief categories, the pattern of belief scores resembles the results from the pre-test: For Belief $1(M d n=2.00)$ and Belief $3(M d n=2.00)$ approximately one third 
112 of the participants still showed no or weak evidence of alignment. The alignment with Belief $4(M d n=1.00)$ is still weaker than for all other beliefs, even though the percentage of PSTs who showed no alignment decreased by half (from 60\% to 29\%). Similarly to the pre-test results, in the post-test PST showed stronger alignment with Belief $2(M d n=3.00)$ than with the other beliefs. Only very few PSTs showed no or weak alignment with this belief.

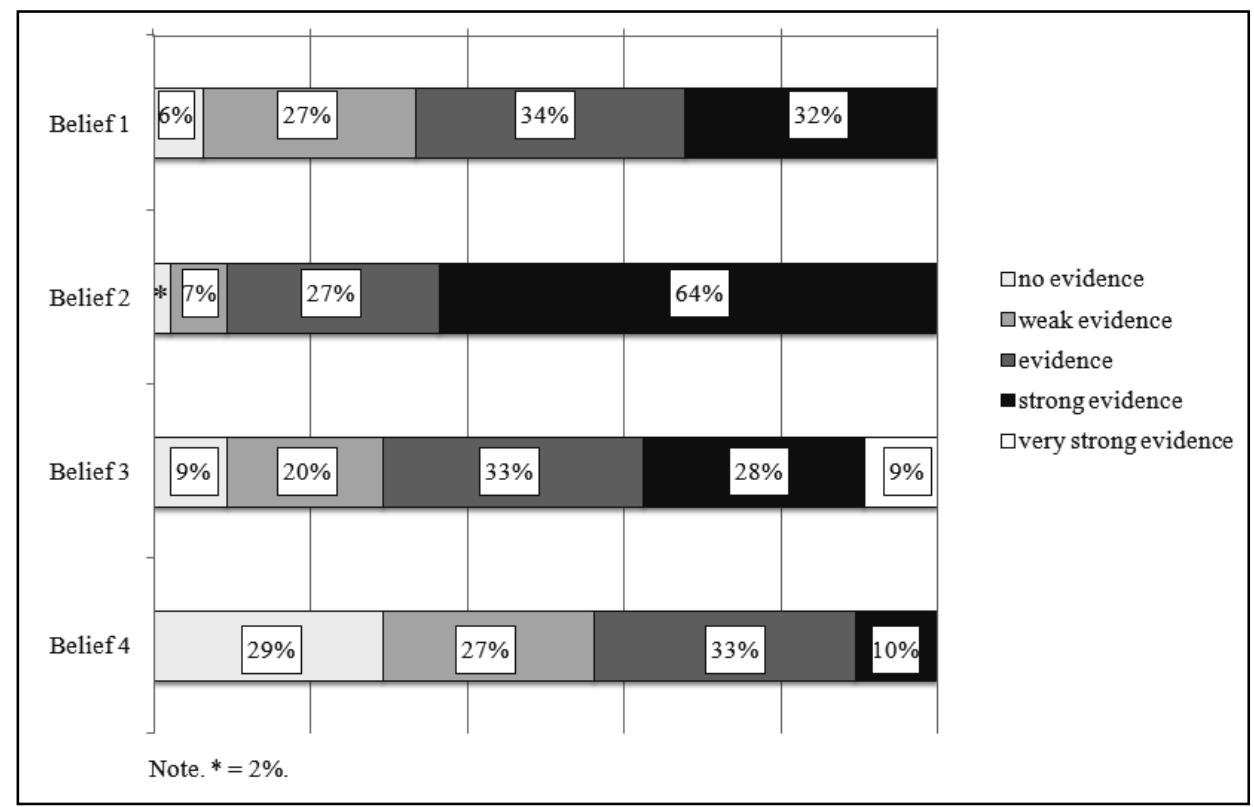

Figure 2 Percentage of participants who showed different levels of alignment with the beliefs measured by the IMAP survey at the end of teacher preparation

To test for LMT treatment effects, Mann-Whitney-U-Tests were used to look for differences at post test. One significant difference was found: the LMT group showed greater alignment with the belief that during interactions related to the learning of mathematics, the teacher should allow children to do as much of the thinking as possible (i.e., Belief 4). Results are displayed in Table 3. Eighteen percent of participants in the LMT group showed no evidence of alignment with the belief $(40 \%$ in the MMC group); $31 \%$ showed weak evidence (23\% in the MMC group); $33 \%$ showed evidence (34\% in the MMC group); and $18 \%$ showed strong evidence of alignment with the belief, whereas only one participant of the MMC group aligned with the belief strongly. 
Table 3 Median belief scores at the end of teacher preparation for each group

\begin{tabular}{ccccc}
\hline \multicolumn{5}{c}{ Median } \\
\hline & LMT & MMC & $U$ & $p$ \\
\hline Belief 1 & 2 & 2 & -0.866 & .386 \\
Belief 2 & 3 & 3 & -1.198 & .231 \\
Belief 3 & 2 & 2 & -0.763 & .445 \\
Belief 4 & 2 & 1 & -2.510 & .012 \\
\hline
\end{tabular}

\section{Discussion}

Findings related to PSTs' incoming beliefs about mathematics teaching and learning confirmed previous studies that have found that prior to teacher preparation, teachers hold beliefs that are typical of a traditional and transmission point of view on teaching (Handal, 2003; Op't Eynde, de Corte, \& Verschaffel, 2002). Specifically, the majority of PSTs in this study's sample did not conceive of mathematics as a web of interrelated concepts and procedures, did not think children can solve mathematics problems in novel ways before being presented with a procedure, and thought teachers should direct instruction. Particularly in relation to Belief 4 (i.e., during interactions related to the learning of mathematics, the teacher should allow the children to do as much of the thinking as possible), participants showed the least alignment, with $81 \%$ of them showing no or weak evidence of alignment with the belief.

Participants showed more alignment with the belief that if students learn mathematical concepts before they learn procedures, they are more likely to understand the procedures when they learn them. If they learn the procedures first, they are less likely ever to learn the concepts. Approximately $50 \%$ of them showed no or weak evidence of alignment with this belief, while the remaining $50 \%$ showed evidence or strong evidence of alignment.

In contrast to some prior studies that have found teacher beliefs to be highly stable (Benbow, 1995; Foss \& Kleinsasser, 1996), in the present study, PSTs' beliefs changed during teacher preparation. Correlations of pre- and post-test data revealed that scores stability was low. PSTs from both LMT and MMC groups considerably improved their alignment with constructivist beliefs. This indicates that teacher preparation experiences might contribute to these changes.

Although the alignment of fieldwork placements to a constructivist approach to mathematics teaching most likely varied across the sample, overall beliefs changed significantly over time and both versions of the mathematics methods course were conducive to these changes. These findings complement those obtained by Philipp et al. (2007). Our study did not include a group of PSTs whose learning relied only on field experiences, thus we cannot confirm or disconfirm Philipp et al.'s (2007) results in that regard. Rather, our study was designed to study the impact of mathematics 
114 methods instruction on belief changes in situations in which fieldwork experiences cannot be controlled - a situation that is very common in U.S. teacher preparation programs. Thus the findings provide evidence that changes in beliefs are possible during teacher preparation even when the quality of fieldwork experiences cannot be evaluated.

Both versions of the mathematics methods courses facilitated changes in beliefs. One significant group difference was found: PSTs in the LMT group showed a greater change in alignment with the belief that the teacher should allow children to do as much of the thinking as possible. This is particularly interesting given that this was the belief with which participants aligned the least prior to teacher preparation, thus conceivably one of the most difficult beliefs to change. While the median score for the $M M C$ at the end of teacher preparation was 1, the lowest among the belief scores at posttest, it equaled to 2 for the LMT group. Sixty-three percent of PSTs in the MMC group showed no or weak alignment with this belief compared to $49 \%$ of PSTs in the LMT group at the end of teacher preparation, and while $18 \%$ of LMT PSTs showed strong evidence of alignment, only one MMC PSTs fell in this category.

In addition, even though there were no significant group differences for Belief 3 , the percentage of PSTs belonging to the different categories of change scores for this belief differed in the LMT and MMC groups: almost half of PSTs in the LMT group showed a large increase (46\%) of alignment with this belief and only $28 \%$ of PSTs in the MMC group changed their belief to this extent (see Table 2).

Thus, notwithstanding variations in field placements which, given random assignment of participants to groups, most likely varied equally between groups, the video-enhanced course provided experiences that facilitated changes in Belief 4 (and to some extent in Belief 3 ) that were greater than the changes facilitated by the MMC course. To note is that in Philipp et al.'s study (2007) there were no significant differences in alignment changes with Belief 4 in groups who analyzed student thinking through video only, or a combination of video and controlled classroom visits, and the group who did not participate in these opportunities and did not complete fieldwork experiences (i.e., the control group). In other words, the monitored analysis of student thinking in their study did not make a difference for changes in this belief. At the same time, participating in field experiences only resulted to be detrimental (i.e., only small percentages of PSTs in their field experiences groups showed changes in this belief). Similarly, these authors did not find significant differences in Belief 3 changes for PSTs who participated in their video-enhanced experience and those belonging to the control group (while field experiences only were again detrimental). To the contrary, in the present study, for PSTs in the LMT both Belief 3 and Belief 4 changed to a greater extent than for PSTs in the MMC (and significantly so in the case of Belief 4 ) despite the fact that both groups participated in field experiences.

Both findings (i.e., belief changes in both groups and the group difference for Beliefs 3 and 4) are in contrast with results discussed by researchers who in their studies did not find changes in PSTs' beliefs during teacher preparation, such as Foss and 
Kleinsasser (1996, p. 439), who argued that "regardless of what they are presented during their methods course, they [pre-service elementary teachers] begin and end with similar perceptions and beliefs about mathematics teaching and learning."

We think that video examples of successful lessons, in which children were shown solving problems in novel ways before their teachers taught them how to solve them and were allowed to make their thinking explicit through written work or discussions, gave PSTs confidence that this is a feasible and effective approach to mathematics teaching, even in cases in which they were not able to observe this approach during fieldwork and were exposed to more tradition teacher-centered teaching. Perhaps an important difference between our intervention and that investigated in Philipp et al.'s study (2007) is that we utilized several videos in which children were portrayed explaining their thinking and solving problems in the contexts of classroom lessons, thus providing images closer to the reality of everyday teaching than those portrayed in video of students solving mathematics problems individually in front of an interviewer.

The structured analysis and collaborative discussion of these videos also most likely contributed to changes in this belief. Discussions often allow teachers to become aware of their assumptions about teaching and learning as they confront them with those held by others. Awareness is an important first step in changing one's beliefs. Finally, the opportunity to experiment with this type of teaching approach and to reflect on student thinking as portrayed in video of one's own teaching might have influenced participants' belief change as well.

Our data does not allow us to distinguish among all these potential contributing factors. These are thus only hypotheses that could be further explored in the future through interviews with participating PSTs or through studies that control for various factors. Nonetheless this study's findings provide important evidence in support of the use of guided and collaborative analysis of video of classroom lessons in teacher preparation. Belief 4 is particularly crucial within a constructivist approach to teaching: When teachers direct instruction to a great extent and do not provide opportunities for children to make their mathematical thinking visible, it is hard for them to truly build on children's initial understandings as promoted by constructivist approaches.

On the other hand, the video-enhanced course did not provide any additional advantage to PSTs in relation to the other two beliefs that were measured in this study. Both courses (despite variations in individual teachers' field placements) were equally effective at increasing alignment with the beliefs that: 1) Mathematics is a web of interrelated concepts and procedures (and school mathematics should be too); 2) If students learn mathematical concepts before they learn procedures, they are more likely to understand the procedures when they learn them. If they learn the procedures first, they are less likely ever to learn the concepts. This indicates that the analysis of videos of classroom lessons might be less important in relation to these beliefs and other opportunities to learn about conceptually-driven mathematics teaching might be as beneficial. 


\section{Implications and future directions}

Various implications for the practice of teacher preparation can be drawn from this study's results. Differences in incoming beliefs should be assessed by method instructors at the beginning of teacher preparation. Discussion groups could then be created that involve PSTs with different beliefs to facilitate confrontation. This would also help future teachers become aware of their beliefs, a first important step in working toward belief change. In addition, specific learning activities could be designed for PSTs who show the least alignment with constructivist beliefs.

When addressing beliefs most closely related to classroom practice, such as belief 4 in this study, video seems to be a promising tool to offer PSTs concrete images of successful examples of constructivist teaching. Accompanying analysis and reflection activities can further facilitate changes in these types of beliefs.

An important next step of this research will be to examine participants' beliefs over time. Research suggests that although PSTs may develop progressive beliefs during teacher preparation, they fall back into more traditional beliefs once they enter the profession (Müller-Fohrbrodt, Cloetta, \& Dann, 1978). It will be thus interesting to examine participants' beliefs during the first few years of teaching as part of the longitudinal component of the larger project. Finally, another important question is whether an alignment with constructivist beliefs results in student-centered teaching practices. This is a question we plan to pursue in future research.

\section{References}

Ambrose, R., Clement, L., Philipp, R., \& Chauvot, J. (2004). A web-based survey to assess prospective elementary school teachers' beliefs about mathematics and mathematics learning: an alternative to Likert scales. School Science and Mathematics, 104(2), 56-69.

Benbow, R. M. (1995). Mathematics beliefs in an "early teaching experience". Proceedings of the annual conference of the North American chapter of the International group for the psychology of mathematics education. (ERIC Document Reproduction Service No. ED 391662.)

Biedermann, H., Brühwiler, C., \& Steinmann, S. (2012). Making the impossible possible? Establishing beliefs about teaching and learning during teacher training courses. In J. König (Ed.), Teachers' pedagogical beliefs (pp. 37-52). Münster: Waxmann.

Blömeke, S. (2012). Does greater teacher knowledge lead to student orientation? The relationship between teacher knowledge and teacher beliefs. In J. König (Ed.), Teachers pedagogical beliefs (pp. 15-36). Münster: Waxmann.

Borko, H., Jacobs, J., Eiteljorg, E., \& Pittman, M. E. (2008). Video as a tool for fostering productive discussions in mathematics professional development. Teaching and Teacher Education, 24(2), 417-436.

Foss, D. H., \& Kleinsasser, R. C. (1996) Preservice elementary teachers' views of pedagogical and mathematical content knowledge. Teaching and Teacher Education, 12(4), 429-442.

Handal, B. (2003). Teachers' mathematical beliefs: A review. The Mathematics Educator, 13(2), 47-57.

Müller-Fohrbrodt, G., Cloetta, B., \& Dann, H. D. (1978). Der Praxisschock bei jungen Lehrern [Novice teachers' shock in practice]. Stuttgart: Klett Verlag. 
Op’t Eynde, P., De Corte, E., \& Verschaffel, L. (2002). Framing students' mathematics-related beliefs: A quest for conceptual clarity and a comprehensive categorization. In G. Leder, E. Pehkone, \& G. Toerner (Eds.), Beliefs - a hidden variable in mathematics education? (pp. 13-37). Dordrecht: Kluwer.

Pajares, M. F. (1992). Teachers' beliefs and educational research: Cleaning up a messy construct. Review of Educational Research, 62(3), 307-332.

Philipp, R., \& Schappelle, B. (2003). IMAP Web-Based Beliefs Survey Manual. Retrieved from http://www.sci.sdsu.edu/CRMSE/IMAP/Beliefs-Survey_Manual.pdf.

Philipp, R. A. (2007). Mathematics teachers. Beliefs and affect. In F. K. Lester, Jr. (Ed.), Second handbook of research on mathematics teaching and learning (pp. 257-315). Charlotte: Information Age Publishing.

Philipp, R. A., Ambrose, R., Lamb, L. L., Sowder, J. T., Schappelle, B. P., Sowder, L., ... Chauvot, J. (2007). Effects of early field experiences on the mathematical content knowledge and beliefs of prospective elementary school teachers: An experimental study. Journal for Research in Mathematics Education, 38(5), 438-476.

Richardson, V. (1996). The role of attitudes and beliefs in learning to teach. In J. Sikula, T. Buttery, \& E. Guyton (Eds.), Handbook of research on teacher education (pp. 102-119). New York: Macmillan.

Santagata, R., Zannoni, C., \& Stigler, J. W. (2007). The role of lesson analysis in pre-service teacher education: An empirical investigation of teacher learning from a virtual video-based field experience. Journal of Mathematics Teacher Education, 10(2), 123-140.

Santagata, R., \& Guarino, J. (2011). Using video to teach future teachers to learn from teaching. ZDM The International Journal of Mathematics Education, 43(1), 133-145.

Santagata, R., Jovel J., \& Yeh, C. (under review). Learning to analyze teaching: A study of pre-service teachers' group conversations around videos of mathematics teaching.

Schoenfeld, A. H. (2011). Toward professional development for teachers grounded in a theory of decision making. Mathematics Education, 43(4), 457-469.

Wang, J., \& Hartley, K. (2003). Video technology as a support for teacher education reform. Journal of Technology and Teacher Education, 11(1), 105-138.

Sonja Mohr

Technical University of Berlin, Humanities, Institute of Education, Department of Educational Psychology Marchstr. 23, 10587 Berlin, Germany sonja.mohr@tu-berlin.de

Rossella Santagata University of California, School of Education, Irvine 3200 Education Building, Irvine, CA 92697, USA 